\begin{tabular}{|c|l|}
\hline Title & Effects of non-B DNA sequences on transgene expression \\
\hline Author(s) & Kamiya, Hiroyuki; Goto, Hitomi; Harashima, Hidey oshi \\
\hline Citation & Journal of Bioscience and Bioengineering, 108(1), 20-23 \\
\hline https://doi.org/10.1016/.jbiosc.2009.02.013 \\
\hline Issue Date & $2009-07$ \\
\hline Doc URL & http://hdl.handle.net/2115/38996 \\
\hline Rights & ○ 2009 The Society for Biotechnology, Japan \\
\hline Type & article (author version) \\
\hline File Information & NES-pDNA.pdf \\
\hline
\end{tabular}

Instructions for use 


\section{Effects of non-B DNA sequences on transgene expression}

\section{Hiroyuki Kamiya*, Hitomi Goto, Hideyoshi Harashima}

Faculty of Pharmaceutical Sciences, Hokkaido University, Kita-12, Nishi-6, Kita-ku, Sapporo 060-0812, Japan

CREST, Japan Science and Technology, Japan

*Corresponding author. e-mail: hirokam@pharm.hokudai.ac.jp

phone $+81-(0) 11-706-3733 \quad$ fax $+81-(0) 11-706-4879$

Running title: Effects of non-B DNA sequences on transgene expression

DNA conformation may be an important factor affecting gene transcription. In this study, we examined how DNA sequences with unusual conformations affect transgene expression. $\mathrm{A}_{30}$ and $(\mathrm{CG})_{15}$ sequences that can adopt the $\mathrm{B}^{\prime}$ and $\mathrm{Z}$ conformations, respectively, were introduced into a $\beta$-actin promoter. Luciferase plasmids containing the manipulated promoter were transfected into NIH3T3 cells by electroporation and were delivered into mouse livers with a hydrodynamics-based injection. Expression from plasmid with the $(\mathrm{CG})_{15}$ sequence was multiple times higher than expression from control plasmid DNA. The $\mathrm{A}_{30}$ sequence also tended to enhance expression. These results suggest that non-B DNA sequences could improve transgene expression in cells. 
DNA conformation potentially affects various DNA functions such as transcription and replication. DNA is most commonly found in the B form under normal cellular conditions (1). The presence of DNA sequences that adopt conformation(s) other than the B form might enhance/suppress transcription when they are located near/in regulatory regions.

In this study, we investigated the effects of non-B DNA sequences on transgene expression in cultured cells and mouse livers. We examined two kinds of plasmid DNA containing non-B DNA sequences (Fig. 1 and Table 1). These sequences were inserted between the CCAAT and TATA boxes, which are important recognition sequences for transcription factors. Since BglII and XhoI sites were available for plasmid construction, plasmid DNA containing the human $\beta$-actin promoter was used as the parental plasmid. In addition, the length of these sequences was fixed at 30 to avoid changes in transgene expression due to varying distances between the CCAAT and TATA boxes in the promoter.

Previously, Shimizu et al. showed that poly $(\mathrm{dA}) \bullet \operatorname{poly}(\mathrm{dT})$ tracts adopt a B' conformation (2). The $\mathrm{B}^{\prime}$ conformation is rigid and heteronomous with two sugar-phosphate geometries and a narrow groove (3-5). In addition, it was demonstrated that the poly(dA)•poly(dT) tract structure exists in living cells (6). In this study, an $\mathrm{A}_{30}$ sequence was inserted between the CCAAT and TATA boxes (Fig. 1 and Table 1). The $\mathrm{Z}$ conformation is found in crystalline oligodeoxyribonucleotides like $\mathrm{d}(\mathrm{CGCGCG}) \bullet \mathrm{d}(\mathrm{CGCGCG})$ and is stabilized by high concentrations of $\mathrm{MgCl}_{2}, \mathrm{NaCl}$ or ethanol in solution (7). In Z-DNA conformations, G bases adopt the unusual syn-glycoside and C3'-endo sugar pucker, alternating regularly along the DNA backbone. In this study, $(\mathrm{CG})_{15}$ sequences, which are capable of converting to the Z-conformation under appropriate conditions, were used (Table 1). We found that the 
non-B DNA sequences $\mathrm{A}_{30}$ and $(\mathrm{CG})_{15}$ located between the CCAAT and TATA boxes affected transgene expression, implying that transcriptional factors have different accessibility to plasmids. This result suggests that the presence of non-B DNA sequences improves transgene expression.

\section{MATERIALS AND METHODS}

\section{Materials}

Oligodeoxyribonucleotides were purchased from Sigma Genosys Japan (Ishikari, Japan) and Invitrogen Japan (Tokyo, Japan) in purified forms. The plasmid containing the CCAAT and TATA boxes of the $\beta$-actin promoter and the luciferase gene was constructed by replacement of the cytomegalovirus promoter (the BglII-SacII fragment) of pYK-CMV-luc (8) with the DNA fragment for the $\beta$-actin promoter, which was amplified from human genomic DNA.

Two plasmids containing non-B DNA sequences were constructed by insertion of these sequences between the CCAAT and TATA boxes in the human $\beta$-actin promoter (Fig. 1 and Table 1). Since the wild-type $\beta$-actin promoter contains the serum response element (CCTTTTATGG) that enhances transcription (9) between the CCAAT and TATA boxes, we used the plasmid without this sequence as the control (no plasmid DNA examined in this study contain this element sequence). The plasmids were constructed by DNA cassette mutagenesis using the BglII and XhoI sites (Table 1). Oligodeoxyribonucleotide duplexes containing the CCAAT box and non-B DNA sequences were inserted into the region upstream of the TATA box in plasmid DNA containing the $\beta$-actin promoter and the luciferase gene (Table 1 and Fig. 1). These 
plasmids were amplified in Escherichia coli strain DH5 $\alpha$ and purified with a Qiagen (Hilden, Germany) EndoFree Plasmid Mega kit.

\section{Electroporation}

The luciferase plasmid DNA (5 $\mu \mathrm{g})$ was introduced into NIH3T3 cells $(2 \mathrm{X}$ $10^{6}$ cells $)$ by electroporation $(0.3 \mathrm{kV}, 500 \mu \mathrm{F}, 0.4 \mathrm{~cm}$ gap) with a Gene Pulser II (Bio-Rad, Hercules, CA, USA). The cells were suspended in $10 \mathrm{ml}$ of warm Dulbecco's modified Eagle medium with $10 \%$ fetal calf serum and transferred into a 10 -cm dish. The cells were incubated under $5 \% \mathrm{CO}_{2} /$ air at $37^{\circ} \mathrm{C}$ for $24 \mathrm{hr}$. The cells were washed with phosphate-buffered saline (PBS) twice and then resuspended by trypsinization. After centrifugation at $800 \mathrm{~g}$ for $3 \mathrm{~min}$ at $4^{\circ} \mathrm{C}$, the pellet was washed three times with PBS. Luciferase activity and amount of exogenous DNA were measured as described below.

\section{Hydrodynamics-based injection}

Plasmid DNA (10 $\mu \mathrm{g}$ in $2 \mathrm{ml}$ of saline) was injected into the tail vein of male five week-old Balb/c mice within $5 \mathrm{sec}(10,11)$. The livers were harvested from the injected mice after $24 \mathrm{hr}$, and luciferase activity and amount of exogenous DNA were measured as described below.

The experimental protocols were approved by the institutional animal care and research advisory committee at the Faculty of Pharmaceutical Sciences, Hokkaido University, Sapporo, Japan.

\section{Luciferase activity}


The pellet of cells transfected by electroporation was resuspended in Reporter Lysis Buffer (Promega, Madison, Wisconsin, USA) (150 $\mu 1$ per 10-cm dish) and was frozen and thawed. After centrifugation at $13,000 \mathrm{~g}$ for $2 \mathrm{~min}$ at $4^{\circ} \mathrm{C}$, the supernatant was examined for luciferase activity using the Luciferase Assay Systems kit (Promega). A $20 \mu 1$ aliquot of the supernatant (total $600 \mu 1$ ) was mixed with the Luciferase Assay Reagent $(50 \mu 1)$ and luminescence was measured for $9 \mathrm{sec}$ with a Luminescencer PSN (Atto, Tokyo, Japan).

Mice livers were minced with scissors and homogenized completely in Lysis Buffer (100 mM Tris-HCl, 2 mM EDTA, 0.1\% Triton X-100, pH 7.8) (1 ml per 0.2 g of liver). After centrifugation at $13,000 \mathrm{~g}$ for $10 \mathrm{~min}$ at $4^{\circ} \mathrm{C}$, a $20 \mu 1$ aliquot of the supernatant was diluted 100-fold and examined for luciferase activity using the Luciferase Assay Systems kit as described above.

\section{Isolation of nuclear DNA and quantitative PCR}

For the electroporated cells, the pellet was resuspended in DNA Lysis Buffer (10 mM Tris- $\mathrm{HCl}, 10 \mathrm{mM} \mathrm{NaCl}, 3 \mathrm{mM} \mathrm{MgCl}$, $0.5 \%$ (w/v) IGEPAL-CA630, $\mathrm{pH}$ 7.4) (800 $\mu 1$ per $10-\mathrm{cm} \mathrm{dish)} \mathrm{(12).} \mathrm{After} \mathrm{centrifugation} \mathrm{at} 1,400 \mathrm{~g}$ for $5 \mathrm{~min}$ at $25^{\circ} \mathrm{C}$, the pellet was washed three times with DNA Lysis Buffer and stored at $-80^{\circ} \mathrm{C}$. Intranuclear DNA was extracted with a SepaGene reagent (Sanko Jun-yaku, Tokyo, Japan).

Mice livers $(0.1 \mathrm{~g})$ were homogenized in a solution containing $30 \mathrm{mM}$ Tris- $\mathrm{HCl}, 100 \mathrm{mM}$ EDTA and $250 \mathrm{mM}$ sucrose at $\mathrm{pH} 7.4(1 \mathrm{ml})$. After centrifugation at $800 \mathrm{~g}$ for $5 \mathrm{~min}$ at $4^{\circ} \mathrm{C}$, the pellet was again washed with PBS $(1 \mathrm{ml})$ and resuspended in DNA Lysis Buffer $(500 \mu \mathrm{l})$. After centrifugation at $1,400 \mathrm{~g}$ for $5 \mathrm{~min}$ at room temperature, the pellet was washed three times with DNA Lysis Buffer. Intranuclear DNA was extracted with a SepaGene reagent. 
Quantitative PCR (Q-PCR) was performed using an ABI 7500 real time PCR system (Applied Biosystems, Foster City, CA, USA) and SYBR-Green chemistry, as described previously (8). A portion of the recovered DNA was analyzed by Q-PCR. The luciferase gene in the isolated nuclei was detected using the following primers: Luc (+), 5'-GGTCCTATGATTATGTCCGGTTATG; Luc (-), 5'-ATGTAGCCATCCATCCTTGTCAAT.

\section{Statistical analysis}

Statistical significance was determined with the Student's $t$-test. $P<0.05$ was considered significant.

\section{RESULTS}

\section{Effects of non-B DNA sequences on transgene expression in cultured cells}

Non-B DNA sequences were inserted between the CCAAT and TATA boxes, important sequences for recognition by transcriptional factors, in the human $\beta$-actin promoter (Fig. 1). The plasmids were constructed by DNA cassette mutagenesis using the BglII and XhoI sites. Twenty-three nucleotides were present between the 3'-end of these sequences and the 5'-T of the TATA box. The luciferase gene was used as the reporter gene. Naked plasmids $(5 \mu \mathrm{g})$ containing non-B DNA sequences were introduced into NIH3T3 cells by electroporation, and luciferase activities and amounts of plasmid DNA were examined after $24 \mathrm{hr}$.

As shown in Table 2, luciferase expression levels from $A_{30}$ and $(C G)_{15}$ plasmids were several times higher than from the control plasmid, and the amounts of 
the plasmid DNA were similar. To account for variations in DNA delivery efficiency in each transfection experiment, expression efficiencies (luciferase activities divided by the amount of plasmid DNA) were normalized relative to expression efficiency of the control plasmid in each experiment. The relative values were used for comparison. Relative expression efficiencies for $\mathrm{A}_{30}$ and $(\mathrm{CG})_{15}$ plasmids were also higher than for the control plasmid, indicating that the introduction of these sequences between the CCAAT and TATA boxes enhanced transgene expression.

\section{Effects of non-B DNA sequences on expression in mouse livers}

The results obtained with NIH3T3 cells prompted us to examine the effects of non-B DNA sequences on transgene expression in vivo. We delivered naked plasmids $(10 \mu \mathrm{g})$ to the livers of male Balb/c mice by hydrodynamics-based injection. This is a rapid, high-volume injection method, and is one of the most efficient transgene expression methods in vivo $(10,11)$. The livers were harvested after $24 \mathrm{hr}$, and luciferase activities and amounts of plasmid DNA were examined.

Luciferase was expressed from the plasmid DNA containing the $(\mathrm{CG})_{15}$ sequence more efficiently than from the control plasmid DNA in the liver (Table 3). The expression also seemed to be higher for the plasmid DNA containing the $A_{30}$ sequence, although the difference was statistically insignificant due to data variations, as often reported for hydrodynamics-based administrations $(10,11)$. This result shows that these non-B DNA sequences could activate transgene expression in vivo.

\section{DISCUSSION}


The objective of this study was to examine how DNA sequences that adopt non-B conformations influence transgene expression. Naked plasmids containing $A_{30}$ and $(\mathrm{CG})_{15}$ sequences between the CCAAT and TATA boxes were introduced into NIH3T3 cells and mouse livers. As shown in Tables 2 and 3, the $(\mathrm{CG})_{15}$ sequence enhanced transgene expression in the cultured cells and the livers. The $A_{30}$ sequence also positively affected the expression in the cultured cells and seemed to function in vivo. Thus, these non-B DNA sequences worked in both dividing cells (NIH3T3) and in non-dividing cells (mouse hepatocytes).

The increased transgene expression induced by $A_{30}$ and $(C G)_{15}$ sequences might be due to enhanced binding of transcriptional factor(s) to the promoter region used in this study. Transcription is initiated by the binding of transcriptional factor(s) to DNA. Since DNA conformation potentially affects the binding, it could be important for transcription regulation $(13,14)$. Ohyama and colleagues showed that eukaryotic promoters have common characteristic mechanical properties $(15,16)$. Unusual DNA conformations could affect mechanical properties, and the unusual local structure near the $\mathrm{A}_{30}$ and $(\mathrm{CG})_{15}$ sequences might enhance the binding of transcriptional factors to the CCAAT and/or TATA boxes.

Alternatively, the effects of the $\mathrm{A}_{30}$ and $(\mathrm{CG})_{15}$ sequences might be attributed to the binding of proteins to these sequences. For example, it has been shown that human double-stranded RNA adenosine deaminase (ADAR1) binds to Z-DNA, and expression of the Z-DNA-binding domain induces substantial transcription of a reporter gene in yeast $(17,18)$. These putative proteins might be transcriptional factors and/or proteins that facilitate the access of transcriptional factors.

Another possibility is that the enhanced transgene expression is caused by nucleosome exclusion. $\mathrm{A}_{30}$ and $(\mathrm{CG})_{15}$ sequences can adopt the $\mathrm{B}^{\prime}$ and $\mathrm{Z}$ conformations, 
respectively. It has been shown that nucleosomes were excluded on poly(dA)•poly(dT) tracts in eukaryotic cells (2). The $\mathrm{B}^{\prime}$ conformation might inhibit histone binding and consequently increase gene expression. It was also shown that $(\mathrm{CG})_{\mathrm{n}}$ in the $\mathrm{Z}$ conformation is not incorporated into nucleosomes (19-21). This unusual structure might inhibit nucleosome formation, resulting in an increase in gene expression.

In this study, we introduced naked plasmids into NIH3T3 cells by electroporation and compared luciferase gene expression (Table 2). We also observed similar results in NIH3T3 cells transfected with plasmids complexed with cationic lipids (data not shown).

It was previously shown that a left-handed curved DNA sequence (bent DNA) could activate mammalian promoters in cultured cells and mouse livers (22-24). Thus, various DNA sequences with unusual conformations could act as regulatory sequences for transgene expression. Low (and transient) transgene expression is a problem in gene therapy with plasmids $(8,25-27)$. Thus, improved transgene expression ("controlled intranuclear disposition") by the introduction of functional DNA sequence(s) could be important for creating practical gene therapies and efficient transfection (25).

Recently, Morohashi et al. reported the effects of poly(dA)•poly(dT) and poly $(\mathrm{dCdG}) \cdot \operatorname{poly}(\mathrm{dCdG})$ located upstream of the TATA box of the $B A R I$ promoter in yeast genomic DNA (28). They found that the insertion of $A_{n}$ and $(C G)_{n}$ sequences increased the expression of $B A R I$, in agreement with our present results. Since similar results were obtained with yeast genomic DNA (Morohashi et al.) and with plasmid DNA (this study), the introduction of non-B DNA sequences could generally enhance expression of a target gene. 
In conclusion, the presence of non-B DNA sequences enhanced transgene expression in cells and mouse livers. This finding suggests that these sequences could be important for controlling transgene expression.

\section{Acknowledgements}

This work was supported in part by Grants-in-Aid from the Ministry of Education, Culture, Sports, Science and Technology of Japan, from the Japan Society for the Promotion of Science and from the Akiyama Foundation. 


\section{REFERENCES}

1. Leslie, A.G., Arnott, S., Chandrasekaran, R., and Ratliff, R.L.: Polymorphism of DNA double helices. J. Mol. Biol., 143, 49-72 (1980).

2. Shimizu, M., Mori, T., Sakurai, T., and Shindo, H.: Destabilization of nucleosomes by an unusual DNA conformation adopted by poly $(\mathrm{dA}) \cdot \operatorname{poly}(\mathrm{dT})$ tracts in vivo. EMBO J., 19, 3358-3365 (2000).

3. Alexeev, D.G., Lipanov, A.A., and Skuratovskii, I.Ya.: Poly(dA)• poly(dT) is a B-type double helix with a distinctively narrow minor groove. Nature, 325, 821-823 (1987).

4. Nelson, H.C.M., Finch, J.T., Luisi, B.F., and Klug, A.: The structure of an oligo(dA)•oligo(dT) tract and its biological implications. Nature, 330, 221-226 (1987).

5. Park, H.S., Arnott, S., Chandrasekaran, R., Millane, R.P., and Campagnari, F.: Structure of the alpha-form of poly[d(A)]•poly[d(T)] and related polynucleotide duplexes. J. Mol. Biol., 197, 513-523 (1987).

6. Suter, B., Schnappauf, G., and Thoma, F.: Poly $(\mathrm{dA} \bullet \mathrm{dT})$ sequences exist as rigid DNA structures in nucleosome-free yeast promoters in vivo. Nucleic Acids Res., 28, 4083-4089 (2000).

7. Blackburn, G.M. and M.J. Gait (Ed.) (1990) Nucleic Acids in Chemistry and Biology. IRL Press at Oxford University

8. Ochiai, H., Harashima, H., and Kamiya, H.: Intranuclear disposition of exogenous DNA in vivo: Silencing, methylation and fragmentation. FEBS Lett., 580, 918-922 (2006). 
9. Orita, S., Makino, K., Kawamoto, T., Niwa, H., Sugiyama, H., and Kakunaga, T.: Identification of a site that mediates transcriptional response of the human beta-actin gene to serum factors. Gene, 75, 13-19 (1989).

10. Zhang, G., Budker, V., and Wolff, J.A.: High levels of foreign gene expression in hepatocytes after tail vein injections of naked plasmid DNA. Hum. Gene Ther., 10, 1735-1737 (1999).

11. Liu, F., Song, Y., and Liu, D. Hydrodynamics-based transfection in animals by systemic administration of plasmid DNA. Gene Ther., 6, 1258-1266 (1999).

12. Tachibana, R., Harashima, H., Ide, N., Ukistu, S., Ohta, Y., Suzuki, N., Kikuchi, H., Shinohara, Y., and Kiwada, H.: Quantitative analysis of correlation between number of nuclear plasmids and gene expression activity after transfection with cationic liposomes. Pharm Res., 19, 377-381 (2002).

13. Dai, X. and Rothman-Denes, L. B.: DNA structure and transcription. Current Opinion in Microbiology, 2, 126-130 (1999).

14. Hirota, Y. and Ohyama, T.: Adjacent upstream superhelical writhe influences an Escherichia coli promoter as measured by in vivo strength and in vitro open complex formation. J. Mol. Biol., 254, 566-578 (1995).

15. Fukue, Y., Sumida, N., Nishikawa, J., and Ohyama, T.: Core promoter elements of eukaryotic genes have a highly distinctive mechanical property. Nucleic Acids Res., 32, 5834-5840 (2004).

16. Fukue, Y., Sumida, N., Tanase, J., and Ohyama, T.: A highly distinctive mechanical property found in the majority of human promoters and its transcriptional relevance. Nucleic Acids Res., 33, 3821-3827 (2005). 
17. Herbert, A., Alfken, J., Kim, Y.G., Mian, I.S., Nishikura, K., and Rich, A.: A Z-DNA binding domain present in the human editing enzyme, double-stranded RNA adenosine deaminase. Proc. Natl. Acad. Sci. USA, 94, 8421-8426 (1997).

18. Oh, D.B., Kim, Y.G., and Rich, A.: Z-DNA-binding proteins can act as potent effectors of gene expression in vivo. Proc. Natl. Acad. Sci. USA, 99, 16666-16671 (2002).

19. Garner, M.M. and Felsenfeld, G.: Effect of Z-DNA on nucleosome placement. J. Mol. Biol., 196, 581-590 (1987).

20. Casasnovas, J.M. and Azorin, F.: Supercoiled induced transition to the Z-DNA conformation affects the ability of a $\mathrm{d}(\mathrm{CG} / \mathrm{GC})_{12}$ sequence to be organized into nucleosome-cores. Nucleic Acids Res., 15, 8899-8918 (1987).

21. Ausio, J., Zhou, G., and van Holde, K.: A reexamination of the reported B $\rightarrow Z$ DNA transition in nucleosomes reconstituted with poly (dG-m $\left.{ }^{5} \mathrm{dC}\right) \bullet$ poly(dG-m $\left.{ }^{5} \mathrm{dC}\right)$. Biochemistry, 26, 5595-5599 (1987).

22. Nishikawa, J., Amano, M., Fukue, Y., Tanaka, S., Kishi, H., Hirota, Y., Yoda, K., and Ohyama, T.: Left-handedly curved DNA regulates accessibility to cis-DNA elements in chromatin. Nucleic Acids Res., 31, 6651-6662 (2003).

23. Sumida, N., Nishikawa, J., Kishi, H., Amano, M., Furuya, T., Sonobe, H., and Ohyama, T. A designed curved DNA segment that is a remarkable activator of eukaryotic transcription. FEBS J., 273, 5691-5702 (2006).

24. Kamiya, H., Fukunaga, S., Ohyama, T., and Harashima, H.: The location of the left-handedly curved DNA sequence affects exogenous DNA expression in vivo. Arch. Biochem. Biophys., 461, 7-12 (2007). 
25. Kamiya, H., Akita, H., and Harashima, H. Pharmacokinetic and pharmacodynamic considerations in gene therapy. Drug Discov. Today, 8, 990-996 (2003).

26. Ochiai, H., Harashima, H., and Kamiya, H. Silencing of exogenous DNA in cultured cells. Biol. Pharm. Bull., 29, 1294-1296 (2006).

27. Ochiai, H., Fujimuro, M., Yokosawa, H., Harashima, H., and Kamiya, H.: Transient activation of transgene expression by hydrodynamics-based injection may cause rapid decrease in plasmid DNA expression. Gene Ther., 14, 1152-1159 (2007).

28. Morohashi, N., Yamamoto, Y., Kuwana, S., Morita, W., Shindo, H., Mitchell, A.P., and Shimizu, M.: Effect of sequence-directed nucleosome disruption on cell-type-specific repression by $2 / \mathrm{Mcm} 1$ in the yeast genome. Eukaryotic Cell, 5, 1925-1933 (2006). 


\section{FIGURE LEGENDS}

FIG. 1. Structure of the luciferase-plasmids containing a non-B DNA sequence and a $\beta$-actin promoter. The hatched box corresponds to the non-B DNA sequence shown in Table 1. CCAAT, CCAAT box; TATA, TATA box; luc, luciferase gene; amp ${ }^{r}$, E. coli ampicillin resistance gene; ori, E. coli replication origin. 


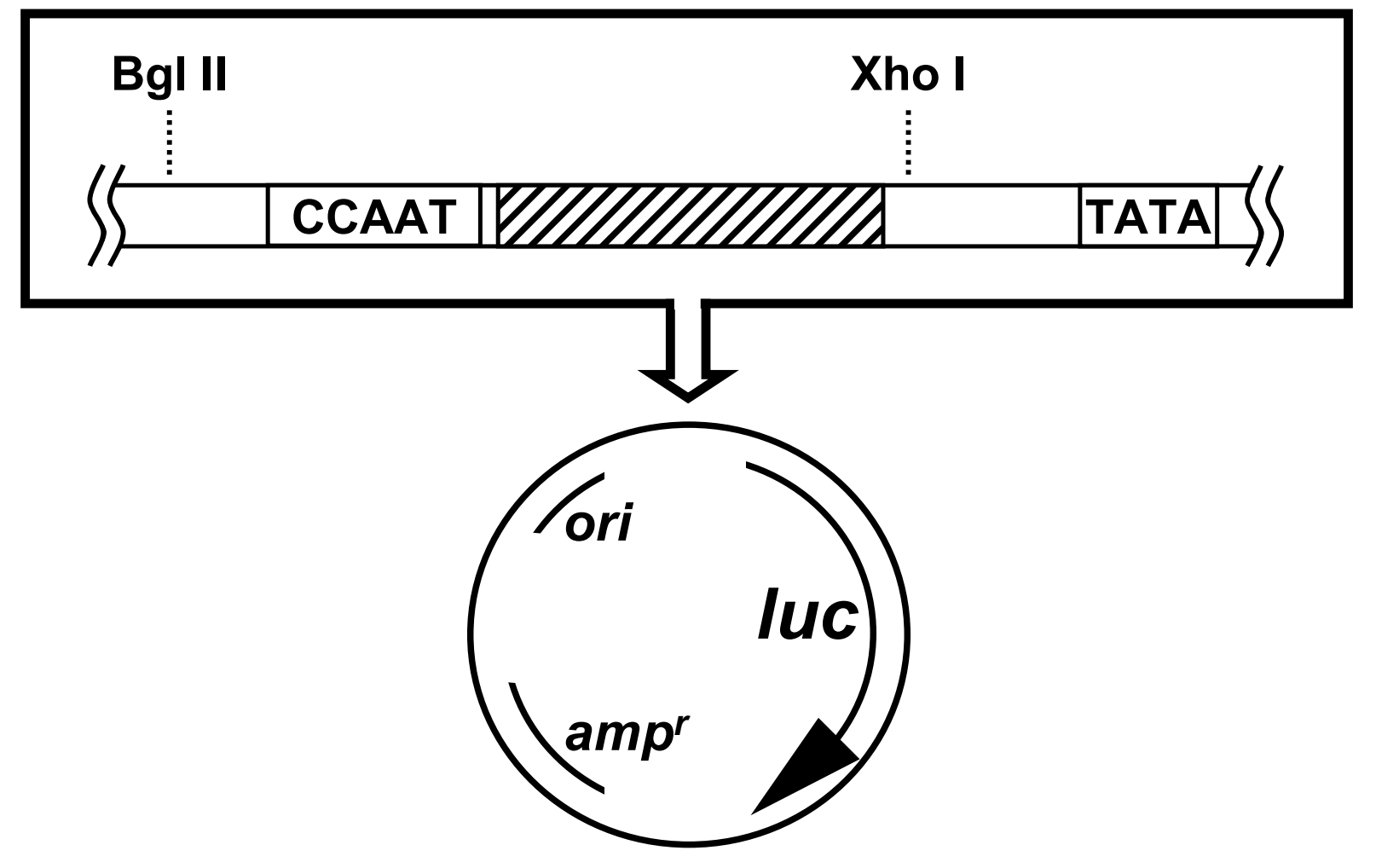

Fig. 1 
TABLE 1. Double-stranded oligodeoxyribonucleotides used for construction of plasmid DNAs with non-B DNA sequences

\begin{tabular}{|c|c|}
\hline plasmid & sequence $^{a}$ \\
\hline $\mathrm{A}_{30}$ & $\begin{array}{l}\text { GATCTCCCGGGCCAATCGCAAAAAAAAAAAAAAAAAAAAAAAAAAAAAAC } \\
\text { AGGGCCCGGTTAGCGTTTTTTTTTTTTTTTTTTTTTTTTTTTTTGAGCT }\end{array}$ \\
\hline$(\mathrm{CG})_{15}$ & $\begin{array}{l}\text { GATCTCCCGGGCCAATCGCCGCGCGCGCGCGCGCGCGCGCGCGCGCGCGC } \\
\text { AGGGCCCGGTTAGCGGCGCGCGCGCGCGCGCGCGCGCGCGCGCGCGAGCT }\end{array}$ \\
\hline control & $\begin{array}{l}\text { GATCTCCCGGGCCAATCGCGGATCCCGCCGGGTATTTTTTTCTAGTATTC } \\
\text { AGGGCCCGGTTAGCGCCTAGGGCGGCCCATAAAAAAAGATCATAAGAGCT }\end{array}$ \\
\hline
\end{tabular}

a) The 30mer sequences corresponding to non-B DNA sequences are shown in bold. The CCAAT box is underlined. The double-stranded oligodeoxyribonucleotides contain ends that are compatible with the BgIII- and XhoI-cleaved ends within the cloning site (GATC and TCGA, respectively). 
TABLE 2. Effects of non-B DNA sequences on luciferase expression upon electroporation ${ }^{\mathrm{a}}$

\begin{tabular}{|c|c|c|c|}
\hline plasmid & $\begin{array}{c}\text { luciferase activity } \\
\left.\text { (X } 10^{4} \mathrm{RLU} / \mathrm{mg} \text { protein }\right)\end{array}$ & $\begin{array}{l}\text { amount of luciferase DNA } \\
\text { (X } 10^{8} \text { copies } / \mu \mathrm{g} \text { total DNA) }\end{array}$ & $\begin{array}{l}\text { relative expression } \\
\text { efficiency }^{\mathrm{b}}\end{array}$ \\
\hline control & $3.36 \pm 2.00$ & $1.88 \pm 2.20$ & 1 \\
\hline $\mathrm{A}_{30}$ & $14.96 \pm 11.82$ & $2.17 \pm 2.65$ & $3.67 \pm 2.20 *$ \\
\hline$(\mathrm{CG})_{15}$ & $17.80 \pm 7.28 * *$ & $1.18 \pm 1.29$ & $8.66 \pm 6.03 *$ \\
\hline
\end{tabular}

${ }^{a}$ Various plasmid DNAs were introduced into NIH3T3 cells by electroporation. The cells were harvested, and the luciferase activities and the amounts of the exogenous DNA were measured. The values represent the averages $\pm \mathrm{SD}$ of five separate experiments. $\left({ }^{*} P<0.05, * * P<0.01\right)$

${ }^{\mathrm{b}}$ The ratio of the luciferase activity to the amount of the exogenous DNA was normalized relative to that for the control plasmid in each experiment. 
TABLE 3. Effects of non-B DNA sequences on luciferase expression upon hydrodynamics-based injection $^{\mathrm{a}}$

$\begin{array}{lccc}\text { plasmid } & \begin{array}{c}\text { luciferase activity } \\ \left(X 10^{4} \mathrm{RLU} / \mathrm{mg} \text { protein }\right)\end{array} & \begin{array}{c}\text { amount of luciferase DNA } \\ \left(\mathrm{X} 10^{8} \text { copies } \mu \mathrm{\mu g} \text { total DNA }\right)\end{array} & \begin{array}{c}\text { relative expression } \\ \text { efficiency }\end{array} \\ \text { control } & 2.94 \pm 3.01 & 2.97 \pm 2.67 & 1 \\ \mathrm{~A}_{30} & 12.60 \pm 7.73 & 5.26 \pm 2.12 & 3.07 \pm 2.24 \\ (\mathrm{CG})_{15} & 10.13 \pm 3.21 * & 4.67 \pm 3.96 & \\ & & & \end{array}$

a Various plasmid DNAs were introduced into mouse liver by hydrodynamics-based injection. The livers were harvested, and the luciferase activities and the amounts of the exogenous DNA were measured. The values represent the averages $\pm \mathrm{SD}$ of four to five separate experiments. $(* P<0.05)$

${ }^{b}$ The ratio of the luciferase activity to the amount of the exogenous DNA was normalized relative to that for the control plasmid in each experiment. 